\title{
FEISTAUER, Daniela, Aufstiegschancen des Adels der preußischen Provinz Sachsen in Staat und Militär 1815-1871
}

Thierry Jacob

\section{OpenEdition}

Journals

Édition électronique

URL : http://journals.openedition.org/ifha/636

DOI : 10.4000/ifha.636

ISSN : 2198-8943

Éditeur

IFRA - Institut franco-allemand (sciences historiques et sociales)

Référence électronique

Thierry Jacob, «FEISTAUER, Daniela, Aufstiegschancen des Adels der preußischen Provinz Sachsen in Staat und Militär 1815-1871 », Revue de l'IFHA [En ligne], Date de recension, mis en ligne le 01 janvier 2007, consulté le 22 septembre 2020. URL : http://journals.openedition.org/ifha/636 ; DOI : https:// doi.org/10.4000/ifha.636

Ce document a été généré automatiquement le 22 septembre 2020.

(CIFHA 


\title{
FEISTAUER, Daniela,
}

\section{Aufstiegschancen des Adels der preußischen Provinz Sachsen in Staat und Militär 1815-1871}

\author{
Thierry Jacob
}

1 Issu d'une thèse de doctorat soutenue à l'université de Greifswald en 2003, cet ouvrage cherche à savoir selon quels mécanismes et motivations et avec quel succès la noblesse a su se hisser, dans les deux premiers tiers du XIXe s., au sein des carrières civiles (administratives) et militaires de la monarchie prussienne. Cette approche rompt donc avec une définition statique de la noblesse comme « élite traditionnelle » occupant de facto et de jure les positions dirigeantes pour donner la priorité à la description des choix, des possibilités, des échecs et des réussites ainsi que des parcours professionnels. Pour ce faire, D.F. fait porter ses recherches sur la province prussienne de Saxe, province constituée en 1815 à partir de territoires prussiens, saxons et de l'Électorat de Mayence (l'Eichsfeld et la région de Erfurt) et qui rassemble trois formations nobiliaires d'origine et de structures différentes dont D.F étudie les capacités diverses à s'intégrer dans le nouvel État prussien au long d'un permanent exercice de comparaison. Non dénué d'originalité, l'ouvrage intègre en revanche faiblement les apports récents d'une historiographie de la noblesse en plein renouvellement conceptuel et thématique, ce que confirme l'absence de nombreux titres au sein de la bibliographie.

2 Le choix méthodologique retenu est celui d'une analyse prosopographique plaçant les liens de famille, d'amitié, de sociabilité ainsi que les réseaux de patronage et d'information au sein du monde du pouvoir au cœur de l'analyse de l'accès de la noblesse aux carrières du service de l'État. L'ouvrage regorge ainsi d'exemples individuels ou familiaux dont l'abondance confère néanmoins un caractère trop descriptif et peu systématique à la rédaction. Après une tentative de définition de ce qu'est une noblesse provinciale et une présentation du jeu d'intégration de ces trois noblesses dans les nouvelles structures provinciales, l'auteur étudie les trajectoires de 
formation et d'éducation des jeunes nobles ainsi que leurs modalités de préparation à la condition de fonctionnaire ou d'officier. Ces carrières se font d'ailleurs de façon ultradominante au bénéfice du service des armes, ce que montre le suivi des professions des membres de dix familles différentes. Le chapitre "Relations et protections " qui, curieusement, ne recourt pas au concept de réseau, offre une illustration de la pertinence de la méthode prosopographique. La question de l'évolution des modalités de recrutement dans les carrières et du poids de la concurrence bourgeoise demeure en revanche absente de l'analyse. L'influence ou non de la disposition d'un domaine sur les choix professionnels et le déroulement de la carrière est également un critère passé en revue. En revanche, les chapitres sur les attitudes politiques (forcément conservatrices), même si D.F. traite également des frictions et méfiances entre noblesse et État monarchique, et sur la carrière de Landräte n'apportent pas d'éléments bien probants ou nouveaux.

Thierry JACOB (Université Lumière - Lyon II) 